\title{
Follow Up of Hypertensive Patients at Regional Hospital of Bafoussam, West Cameroon: Biochemical Profiles in Naive and Hypotensive Drug Treated Patients
}

\author{
Vanessa Linda Nzesseu ${ }^{1}$, Charles Kouam Kouam ${ }^{2}$, Jean-de-Dieu Tamokou ${ }^{1}$, Jules-Roger Kuiate ${ }^{1}$ \\ ${ }^{1}$ Department of Biochemistry, Faculty of Science, University of Dschang, Dschang, Cameroon \\ ${ }^{2}$ Department of Internal Medicine, Bafoussam Regional Hospital, Bafoussam, Cameroon \\ Email: ${ }^{* j t a m o k o u @ y a h o o . f r ~}$
}

How to cite this paper: Nzesseu, V.L., Kouam, C.K., Tamokou, J.-de-D. and Kuiate, J.-R. (2020) Follow Up of Hypertensive Patients at Regional Hospital of Bafoussam, West Cameroon: Biochemical Profiles in Naive and Hypotensive Drug Treated Patients. World Journal of Cardiovascular Surgery, 10, 167-185.

https://doi.org/10.4236/wjcs.2020.109020

Received: August 14, 2020

Accepted: September 18, 2020

Published: September 21, 2020

Copyright $\odot 2020$ by author(s) and Scientific Research Publishing Inc. This work is licensed under the Creative Commons Attribution International License (CC BY 4.0).

http://creativecommons.org/licenses/by/4.0/

\section{(c) (i) Open Access}

\begin{abstract}
Objective: The aim of this work was to study the effects of antihypertensive therapies on certain metabolic parameters in hypertensive patients. Methods: A cross-sectional and analytical study conducted within the Bafoussam Regional Hospital on 343 patients including 99 normotensives and 244 hypertensives distributed in 71 patients naive to treatment and 173 patients under treatment (84 under monotherapy, 67 under bitherapy and 21 under tritherapy). The antihypertensive medications were recorded from the medical records. A questionnaire survey was administered to study participants and potential risk factors for hypertension sought. Blood and urine samples were collected for lipid, renal and hepatic disorder analysis. Two blood pressure measurements enabled us to diagnose hypertensive patients. Measurements of biochemical parameters such as total cholesterol, HDL-cholesterol, LDL-cholesterol, triglycerides, creatinine, glucose, aspartate aminotransferase (ASAT), alanine aminotransferase (ALT), potassium, chloride and calcium were done in serum by methods resulting from commercial kits. Results: Calcium Channel Blockers were significantly associated with increases in blood potassium (odd-ratios $(\mathrm{OR})=8.63, p=0.036)$ and sodium $(\mathrm{OR}=0.20$, $p=0.037)$. Angiotensin-converting enzyme/Angiotensin II receptor blockers were significantly associated with an increase in plasma activity of ASAT (OR $=0.12, p=0.03)$ whereas Diuretics were significantly associated with an increase in ALAT plasma activity ( $\mathrm{OR}=0.003, p=0.012)$. Dual therapies were associated with highest frequencies of hypercreatininemia $(41.8 \%)$ and hyperglycemia (44.8\%) whereas hypocholesterolemia HDL (38.1\%) was most observed in hypertensive patients on triple therapy. The different therapies
\end{abstract}


resulted in very low frequencies of abnormal liver profiles (in general almost all below 10\%). Tritherapy had the most beneficial effects on the different profiles, with no cases of hyperkalemia, glycosuria, hypochloremia, hematuria, hyponatremia, total hypercholesterolemia, ALAT and ASAT hyperactivity. Conclusion: Triple therapy should be recommended as it has the most beneficial effects on metabolic parameters in the study population.

\section{Keywords}

Antihypertensives, Therapy, Metabolic Abnormalities

\section{Introduction}

High blood pressure (hypertension) is the permanent rise in blood pressure with figures above $140 / 90 \mathrm{mmHg}$ which ideally is $120 / 80 \mathrm{mmHg}$. It is a common disease that increases with age and has a hereditary component. Hypertension has consequences on several organs including the heart, arteries and kidneys [1]. Chronic high blood pressure can cause blood vessels in the brain to burst or clog more easily, leading to a stroke [2]. It can also cause vision problems by straining the vessels in the eyes (Heart failure can result from heart enlargement causing failure in supplying blood to the body while heart attack can result from damages of arteries that can become blocked. Hypertension can damage the arteries around the kidneys and interfere with their ability to effectively filter blood be erectile dysfunction in men or lower libido in women [3]. It is associated with abnormalities in carbohydrate metabolism (insulin resistance, hyperglycemia and glucose intolerance) and in lipid metabolism (increased triglycerides, total cholesterol, LDL cholesterol and decreased HDL cholesterol) [4] [5].

Given these possible complications, medical follow-up must take into account screening for damage to the heart, eyes, brain, kidneys and peripheral arteries, side effects of prescribed medications and other associated risk factors, such as hypercholesterolemia and obesity. To overcome this problem, several classes of antihypertensive agents have been developed: beta-blockers, diuretics, angiotensin converting enzyme inhibitors/angiotensin II receptor antagonists, and calcium channel blockers [6]. Despite the effectiveness of antihypertensive drugs, approximately $70 \%$ of hypertensive patients do not achieve the therapeutic goal of blood pressure less than $140 / 90 \mathrm{mmHg}$ with a single class of drug. In 2017, there were recommended new therapeutic objectives of blood pressure less than $130 / 80 \mathrm{mmHg}$, which would be even more difficult to achieve in monotherapy [7]. In addition, many studies have shown the ineffectiveness of monotherapy and would propose a triple therapy for adequate control of blood pressure and its complications [8]. Increasing the dose of monotherapy reduces coronary events and cerebrovascular events by $29 \%$ and $40 \%$ respectively, while dual therapy reduces them by $40 \%$ and $54 \%$, respectively [9]. The need to increase treatment doses as monotherapy increases the side effects of these drugs, which 
are limited by taking small doses of several treatments [10]. On the other hand, the mechanisms leading to hypertension are diverse and monotherapy acts on one or at best two of these mechanisms, while the combination of several classes of treatments would allow action on several different hypertensive mechanisms. It has been noted that dual therapy increases the effect of monotherapy by two to five times [11] [12]. The beneficial effect of the combination of angiotensin-converting enzyme inhibitors and angiotensin receptor blockers on hyperglycemia [13], and that of the beta blockers and thiazides combination on HDL-c increase [14] can be noted. However, either individually or in combination, these antihypertensives affect many metabolic parameters. Beta blockers are associated with loss of glycemic control, insulin resistance and dyslipidemia [15]. Diuretics and thiazides cause hyperglycemia and hyperlipidemia [16]. The combination of beta-blockers and diuretics stimulates insulin resistance [14] whereas the combination of beta-blockers and thiazides increases plasma lipids and blood sugar [13]. In view of these contrasting effects not only of the classes, but also of the combinations on metabolic parameters, we studied the effects of antihypertensive therapies on certain metabolic parameters in hypertensive patients.

\section{Material and Methods}

\subsection{Study Setting}

This study was a cross-sectional and analytical study. It was conducted at the Bafoussam Regional Hospital (West Cameroon) during the period from October 2018 to March 2019. Inclusion criteria: being hypertensive or not, being on antihypertensive medication, being at least 21 years old and giving a favorable opinion for free participation in the study. Non-inclusion criteria: suffering from mental disorders, being pregnant and having refused to sign informed consent. Sample size population determination: this was calculated using the following formula: $\mathrm{n}=\mathrm{Z}^{2} \mathrm{PQ} / \mathrm{d}^{2}$, where $\mathrm{n}$ is the sample size, $\mathrm{P}$ the prevalence, $\mathrm{Q}$ is $1-\mathrm{P}, \mathrm{Z}$ is the statistic corresponding confidence level (1.96), $d$ is precision (0.05). Based on this, the sample size of the study population was estimated at 246 . Finally, 343 individuals were included in this study and subdivided into 3 groups: 99 normotensives, 71 hypertensive naive to drug and 173 drug treated hypertensive (173) participants. The drug treated group was subdivided according to the type of antihypertensive medications. The study protocol was approved by the Regional Ethics Committee Research for Human Health of Center $N^{\circ} 0683$ in Yaoundé at $14^{\text {th }}$ July 2017. Based on this ethical approval, the study was conducted in strict compliance with the physical, moral and psychological integrity of all participants; following the principles outlined in the Helsinki Declaration. The concept of the study was explained to the participants and their writings informed consent sought according to the policy set up by the ministry of public health of Cameroon. Demographic data were appropriately collected with a designed questionnaire. 


\subsection{Definitions}

Cut-off values provided by the Kits were used for the following definitions. Hyperglycemia was defined as fasting plasma glucose levels $\geq 105 \mathrm{mg} / \mathrm{dL}$. Dyslipidemia was defined as: hypertriglyceridemia ( $\mathrm{TG} \geq 1.50 \mathrm{~g} / \mathrm{L}$ ), hypo HDL-cholesterolemia (HDL-c $<0.40 \mathrm{~g} / \mathrm{L}$ ), hyper LDL-cholesterolemia (LDL-c $\geq 1.60 \mathrm{~g} / \mathrm{L}$ ) and hypercholesterolemia (CT $\geq 20 \mathrm{~g} / \mathrm{L}$ ). Ionic homeostasis disorders have been established for values excluded from the following ranges: potassium $(3.6-5 \mathrm{mmol} / \mathrm{L})$, sodium (135 - $145 \mathrm{mmol} / \mathrm{L})$ and chloride $(98-105 \mathrm{mmol} / \mathrm{L})$. Hepatotoxicity was established for values excluded from the following ranges: ASAT $(10-40$ $\mathrm{UI} / \mathrm{ml})$, ALAT $(20-60 \mathrm{UI} / \mathrm{ml}$ ) and nephrotoxicity for values excluded from the following ranges: creatininemia $(6-13 \mathrm{mg} / \mathrm{L})$, hypoglycemia $<0.75 \mathrm{~g} / \mathrm{L}$, hematuria $>0$ red blood cells $/ \mu \mathrm{L}$, proteinuria $>0 \mathrm{~g} / \mathrm{L}$ and glycosuria $>0 \mathrm{mmol} / \mathrm{L}$.

\subsection{Questionnaire Administration and Sample Collection}

After the participants returned their consent forms duly signed, they were each provided with a structured questionnaire to fill. Those who could not read were assisted to fill the questionnaires by the nurses. The questionnaires contained simple closed ended questions regarding known risk factors of hypertension in addition to socio-demographic information. The anti-hypertensive medications were recorded from the medical records. The blood pressure on the day of clinic visit was measured using a manual sphygmomanometer after the patient had rested for at least 10 minutes.

\subsection{Biochemical Analyses}

Biochemical parameters were assayed in urine and blood. The urine of the midstream portion was collected into the sterile container by the patients following the nurse instructions. Blood collection was specifically done by a laboratory technician. Whole blood was collected in free anticoagulant test tube (Becton Dickinson). This blood was allowed to clot by leaving it undisturbed at room temperature for about 30 minutes. The clot was then removed by centrifugation at $3000 \mathrm{rpm}$ for $15 \mathrm{~min}$. The resulting supernatant was the serum. It was immediately transferred into clean polypropylene tube using a Pasteur pipette for biochemical analysis that was carried out within an hour.

In the serum, glucose was quantified using the kinetic method described by Trinder (1969) with the commercial kit Liquick Cor-GLUCOSE from Cormay Laboratories. Triglycerides were quantified using the Liquick Cor-TG commercial kit from Cormay Laboratories. Total cholesterol and HDL-cholesterol were quantified using the Chronolab commercial kit whereas LDL-cholesterol was determined from Friedewald's equation [17]. Creatininemia was quantified by Jaffe's (1886) modified method. The serum activities of alanine aminotransferase (ALAT) and aspartate aminotransferase (ASAT) were measured according to the protocol of commercial kits from Cormay Laboratories. Serum concentrations of $\mathrm{K}^{+}, \mathrm{Na}^{+}$and $\mathrm{Cl}^{-}$ions were measured using the Labcare Diagnostic Kits. 


\subsection{Statistical Analysis}

Data compile from the questionnaire were submitted to ANOVA. Chi square tests were performed to compare continuous and categorical variables, respectively, with statistical significance at $p<0.05$. Odd ratios (ORs) and $95 \%$ confidence intervals (95\% CIs) were estimated using non-conditional logistic regression analyses to evaluate the associations of metabolic disorder factors with the risk of uncontrolled hypertension a baseline. Means of each biochemical parameter in different groups were compared using Waller-Duncan test at $5 \%$ when differences were detected by ANOVA.

\section{Results}

\subsection{General Characteristics of the Study Population}

This study involved 343 patients including 99 normotensives and 244 hypertensives distributed in 71 patients naive to treatment and 173 patients under treatment (Table 1). The study population included 206 women versus 137 men. Among hypertensive patients, more women (63.01\%) than men (36.99\%) were on treatment. Hypertensive patients $(71.1 \%)$ had a higher family history of high blood pressure. The mean ages of the hypertensive patients: 59.61 years and 64.55 years, respectively for untreated and under treatment. Table 1 also shows that participants in the age groups [50 - 60] (27.1\%) and [60 - 70] (26.2\%) were the most represented in the total hypertensive patients. Naive hypertensive patients were significantly $(p<0001)$ more represented in the age groups [50 - 60] (40.8\%) while hypertensive patients on treatment were more represented in the age group [60 - 70] (33.5\%). Whether hypertensive or normotensive, the vast majority said they eat fruits and vegetables while less than $50 \%$ of them confess to practice sports regularly. We found that hypertensive patients in general were four time more smoking than normotensive participants $(p=0.007)$. Alcohol consumption of at least 3 glasses per day is strongly represented in hypertensive patients under treatment (62.6\%) followed by normotensive patients $(31.3 \%)$ and weakly felt in naive patients $(6.1 \%)(p=0.015)$. The frequency of physical activity was also higher among normotensive patients $(52.52 \%)$ than among hypertensive patients ( $40.84 \%$ and $45.09 \%$, respectively for untreated and treated patients) but no significant $(p=0.089)$. Civil servants and workers of the formal sector were significantly $(p=0.001)$ more represented among naive hypertensive and normotensive participants, while they represent only $12.14 \%$ and $1.16 \%$ among hypertensive patients on treatment, respectively. Married participants were most represented in all groups $(55.56 \%, 66.20 \%$ and $70.52 \%$, respectively, in normotensive, untreated hypertensive and treated hypertensive groups), while widower and single were the least represented in normotensive and hypertensive groups $(p=0.001)$. Participant who stopped their study at secondary school were significantly more represented $(p=0.001)$ among normotensive patients (34.34\%) and hypertensive patients under treatment (34.1\%), while illiterate patients were most represented among untreated hypertensive patients (32.39\%). 
Table 1. Demographic characteristics of the study population.

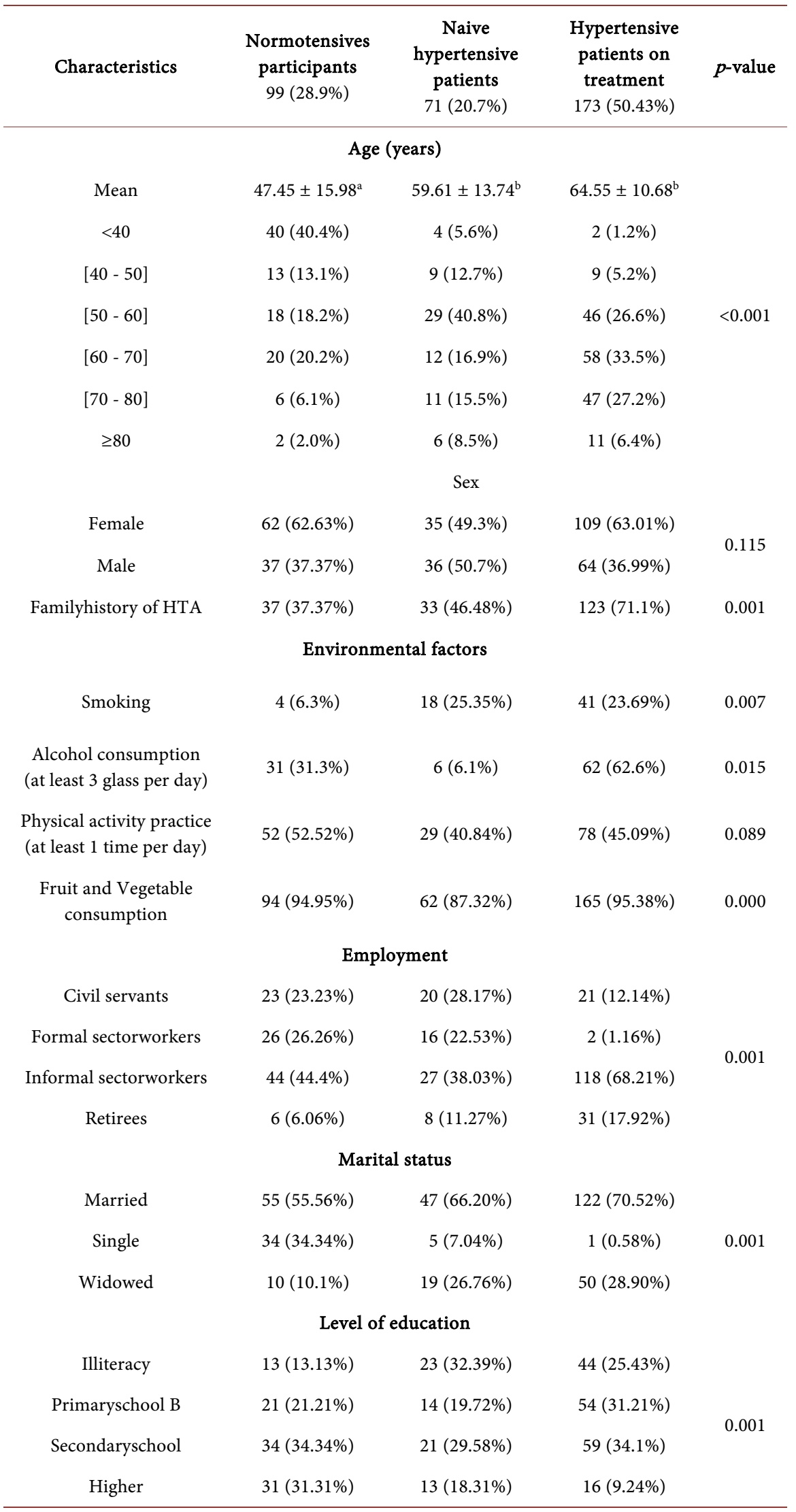




\begin{tabular}{ccccc}
\hline & \multicolumn{3}{c}{ BMI } & \\
Mean $\left(\mathrm{kg} / \mathrm{m}^{2}\right)$ & $27.28 \pm 3.75^{\mathrm{a}}$ & $28.33 \pm 5.56^{\mathrm{a}}$ & $27.97 \pm 5.02^{\mathrm{a}}$ & \\
Normal & $48(48.5 \%)$ & $21(29.6 \%)$ & $61(35.3 \%)$ & 0.001 \\
Overweight $(25<\mathrm{BMI}<30)$ & $11(11.1 \%)$ & $23(32.4 \%)$ & $57(32.9 \%)$ & \\
Obesy $(\mathrm{BMI}<30)$ & $40(40.4 \%)$ & $27(38.0 \%)$ & $55(31.8 \%)$ & \\
Mean $($ pulse/min) & $63.64 \pm 7.14^{\mathrm{a}}$ & $73.55 \pm 9.17^{\mathrm{b}}$ & $80.35 \pm 15.29^{\mathrm{c}}$ & \\
Normal $(60-100)$ & $96(97.20 \%)$ & $70(98.6 \%)$ & $142(82.1 \%)$ & 0.000 \\
Low $(<60)$ & $3(3.0 \%)$ & $0(0.0 \%)$ & $16(9.2 \%)$ & \\
High $(>100)$ & $0(0.0 \%)$ & $1(1.4 \%)$ & $15(8.7 \%)$ & \\
SBP $(\mathrm{mmHg})$ & $123.3 \pm 12.44^{\mathrm{a}}$ & $169.72 \pm 19.53^{\mathrm{b}}$ & $169.58 \pm 19.22^{\mathrm{b}}$ & \\
DBP $(\mathrm{mmHg})$ & $75.44 \pm 8.53^{\mathrm{a}}$ & $96.04 \pm 14.77^{\mathrm{b}}$ & $95.18 \pm 12.35^{\mathrm{b}}$ & 0.000 \\
\hline
\end{tabular}

The values with different letters on the same line are significantly different at $p<0.05$ with student $\mathrm{t}$-test; BMI: Body Mass Index; SBP: Systolic Blood Pressure; DBP: Diastolic Blood Pressure.

Illiterate people were the least represented among normotensive people, while among hypertensive people, it was the highest level. The average body mass index (BMI) for each group was between $27.28 \mathrm{~kg} / \mathrm{m}^{2}$ and $28.33 \mathrm{~kg} / \mathrm{m}^{2}$; no significant difference was noted between the groups. But overweight and obesity were more observed in hypertensive participants $(p=0.001)$. The systolic blood pressures (SBP) for hypertensive patients were $169.72 \mathrm{mmHg}$ and $169.58 \mathrm{mmHg}$, respectively, for untreated and treated patients, compared to $123.33 \mathrm{mmHg}$ for normotensive participants. The means of diastolic blood pressures (DBP) for hypertensive patients were $96.04 \mathrm{mmHg}$ and $95.18 \mathrm{mmHg}$ respectively, for untreated and treated patients, compared to $75.44 \mathrm{mmHg}$ for normotensive participants. No significant differences were noted for SBP and DBP in hypertensive groups. The mean heart rates of hypertensive patients (73.55 and 80.35 pulses/min) were significantly higher than those of normotensive patients (63.64 pulse/min); the pulsation of hypertensive patients on treatment shows a weak disorders (bradycardia 9.2\% and tachycardia 8.7\%) and was also significantly higher than that of untreated patients.

\subsection{Distribution of Participants According to Antihypertensisve Drug Prescription}

The three types of antihypertensive drug combinations for the treatment of patients in the treatment unit of the Bafoussam Regional Hospital (monotherapy, bitherapy and tritherapy) were prescribed to patients with all three grades of hypertension (Table 2). However, differences were observed in the prescription rates of each combination depending on the grade of hypertension. Thus, monotherapy was more prescribed for patients with grade 1 (32.9\%), dual therapy for patients with grade $2(47.8 \%)$ and triple therapy for patients with grade 
Table 2. Distribution of hypertensive according to hypertension grade and type of therapy.

\begin{tabular}{ccccc}
\hline Characteristics & Grade 1 & Grade 2 & Grade 3 & $p$-value \\
\hline Naive & $21(29.6 \%)$ & $32(45.1 \%)$ & $18(25.4 \%)$ & $<0.001$ \\
Under treatment & $47(27.2 \%)$ & $85(49.1 \%)$ & $41(23.7 \%)$ & \\
Type of therapy & & & & \\
Monotherapy & $28(32.9 \%)$ & $36(42.4 \%)$ & $21(24.7 \%)$ & \\
Bitherapy & $15(22.4 \%)$ & $32(47.8 \%)$ & $20(29.9 \%)$ & $<0.01$ \\
Tritherapy & $4(19.0 \%)$ & $17(81.0 \%)$ & $0(0 \%)$ & \\
\hline
\end{tabular}

Grade 1: Systolic 140 - 159 mm Hg and/or diastolic 90 - 99 mm Hg. Grade 2: Systolic 160 - 179 mm Hg or greater and/or diastolic $100-109 \mathrm{~mm} \mathrm{Hg}$. Grade 3: Systolic $180 \mathrm{~mm} \mathrm{Hg}$ or greater and/or diastolic $110 \mathrm{~mm}$ $\mathrm{Hg}$ or greater.

$2(81.0 \%)$. The differences in prescription were significant between grades and types of therapy $(p=0.01)$. Four drug classes were identified in patients with very similar prescription rates $(15.12 \%-16.8 \%)$ except for central antihypertensives $(1.58 \%)$. Only one combination was identified in tritherapy against five in bitherapy, consisting in particular of Calcium Channel Blockers-Diuretics (13.95\%), Angiotensin-converting enzyme/Angiotensin II receptor blockers-Diuretics (20.93\%) extinguish the most prescribed while, Calcium Channel Blockers and Angiotensin-converting enzyme-Angiotensin II receptor blockers (2.91\%), Calcium Channel Blockers-Central Antihypertensive (0.58\%) and Calcium Channel Blockers- $\beta$-blocker (0.58\%) were prescribed less (Table 3 ).

\subsection{Variation of Selected Biochemical Parameters in Naive to Treatment and Treated Patients}

The average values of the contents of minerals, cholesterol, triglyecerides, glycemia and transaminases are not significantly different $(p>0.05)$ in the different treatment groups (Table 4). However, compared to treatment-naive patients, monotherapy, dual therapy, and triple therapy patients had lowest HDL averages, a situation that was sparser for triple therapy. It was the same for the chloremia. LDL levels were significantly higher in patients on therapy compared to those of untreated patients. The ASAT level was significantly highest $(p<0.05)$ in patients on therapy without the type of therapy having a significant influence. Because considering the average per group may hide abnormalities, we determined the prevalence of abnormalities in patients in each treatment group (Table 5). We thus observed that the prevalences of hyponatremia/hypernatremia, hypochloremia/hyperchloremia, hypercholesteronemia, hypertriglyceremia, hypercholesteronemia-HDL, elevated level of ALT, hypercreatinemia, hematuria and glycosuria were not significantly $(p>0.05)$ more marked in patients under treatment only in treatment-naive patients. In contrast, significant differences were observed for the prevalence of hypo/hyperkalaemia $(p=0.0001)$, hypocholesterol-HDL $(p=0.0001)$, hyperglycemia $(p=0.003)$, high ASAT activity ( $p$ $=0.0001)$ and proteinuria $(p=0.034)$. 
Table 3. Distribution of the hypertensive patients according to the therapy types and antihypertensive classes prescribed.

\begin{tabular}{|c|c|c|}
\hline Types of therapy & Anti-hypertensive classes & n (\%) \\
\hline \multirow{4}{*}{$\begin{array}{l}\text { Monotherapy } \\
85(49.13 \%)\end{array}$} & Diuretics & $29(16.86 \%)$ \\
\hline & Calcium Channel Blockers & $29(16.28 \%)$ \\
\hline & $\begin{array}{l}\text { Angiotensin-converting enzyme/Angiotensin II } \\
\text { receptor blockers }\end{array}$ & $26(15.12 \%)$ \\
\hline & Central Antihypertensive & $1(1.58 \%)$ \\
\hline \multirow{5}{*}{$\begin{array}{l}\text { Bitherapy } \\
67(38.95 \%)\end{array}$} & Calcium Channel Blockers and Diuretics & $24(13.95 \%)$ \\
\hline & $\begin{array}{l}\text { Angiotensin-converting enzyme/Angiotensin II } \\
\text { receptor blockers and Diuretics }\end{array}$ & $36(20.93 \%)$ \\
\hline & $\begin{array}{c}\text { Calcium Channel Blockers and } \\
\text { Angiotensin-converting enzyme/Angiotensin II } \\
\text { receptor blockers }\end{array}$ & $5(2.91 \%)$ \\
\hline & $\begin{array}{c}\text { Calcium Channel Blockers and Central } \\
\text { Antihypertensive }\end{array}$ & $1(0.58 \%)$ \\
\hline & Calcium Channel Blockers and $\beta$-blocker & $1(0.58 \%)$ \\
\hline $\begin{array}{l}\text { Tritherapy } \\
21(12.14 \%)\end{array}$ & $\begin{array}{l}\text { Calcium Channel Blockers, } \\
\text { Angiotensin-converting enzyme/Angiotensin II } \\
\text { receptor blockers and Diuretics }\end{array}$ & $21(12.14 \%)$ \\
\hline
\end{tabular}

Table 4. Effect of different types of therapy on selected biochemical parameters of hypertensive patients.

\begin{tabular}{|c|c|c|c|c|c|}
\hline \multirow{2}{*}{ Biochemical Parameters } & \multirow{2}{*}{ Normal range } & \multicolumn{4}{|c|}{ Types of therapy } \\
\hline & & Naive patients & Monotherapy & Bitherapy & Tritherapy \\
\hline Creatininemia & Mean $(6-13 \mathrm{mg} / \mathrm{dl})$ & $10.80 \pm 1.60^{\mathrm{b}}$ & $12.21 \pm 3.82^{\mathrm{a}}$ & $13.50 \pm 3.79^{\mathrm{a}}$ & $12.96 \pm 2.81^{\mathrm{a}}$ \\
\hline Kalemia & Mean $(3.6-5 \mathrm{mmol} / \mathrm{L})$ & $4.44 \pm 0.60^{\mathrm{a}}$ & $4.42 \pm 0.59^{\mathrm{a}}$ & $4.33 \pm 0.68^{\mathrm{a}}$ & $4.32 \pm 0.33^{\mathrm{a}}$ \\
\hline Natremia & Mean (135 - $145 \mathrm{mmol} / \mathrm{L})$ & $143.10 \pm 4.06^{\mathrm{a}}$ & $142.77 \pm 4.96^{\mathrm{a}}$ & $144.24 \pm 4.49^{\mathrm{a}}$ & $143.81 \pm 4.17^{\mathrm{a}}$ \\
\hline Chloremia & Mean (98 - $105 \mathrm{mmol} / \mathrm{L})$ & $100.96 \pm 5.27^{\mathrm{a}}$ & $101.11 \pm 3.87^{\mathrm{a}}$ & $102.31 \pm 4.15^{\mathrm{ab}}$ & $104.19 \pm 3.08^{\mathrm{b}}$ \\
\hline Total cholesterolemia & Mean $(<2 \mathrm{~g} / \mathrm{l})$ & $1.40 \pm 0.35^{\mathrm{b}}$ & $1.79 \pm 0.36^{\mathrm{a}}$ & $1.75 \pm 0.34^{\mathrm{a}}$ & $1.64 \pm 0.28^{\mathrm{a}}$ \\
\hline Cholesterolemia-LDL & Mean $(<1.6 \mathrm{~g} / 1)$ & $0.32 \pm 0.14^{\mathrm{c}}$ & $1.31 \pm 0.33^{\mathrm{a}}$ & $1.20 \pm 0.26^{\mathrm{ab}}$ & $1.14 \pm 0.20^{\mathrm{b}}$ \\
\hline Triglyceridemia & Mean $(<1.5 \mathrm{~g} / \mathrm{l})$ & $1.04 \pm 0.37^{\mathrm{a}}$ & $1.13 \pm 0.48^{\mathrm{a}}$ & $1.03 \pm 0.49^{\mathrm{a}}$ & $1.16 \pm 0.38^{\mathrm{a}}$ \\
\hline Glycemia & Mean $(0.75-1.05 \mathrm{~g} / \mathrm{l})$ & $0.99 \pm 0.19^{\mathrm{b}}$ & $1.07 \pm 0.48^{\mathrm{a}}$ & $1.21 \pm 0.63^{\mathrm{a}}$ & $0.82 \pm 0.16^{c}$ \\
\hline ASAT activity & Mean (10 - $40 \mathrm{UI} / \mathrm{ml})$ & $16.06 \pm 2.59^{b}$ & $27.07 \pm 10.57^{\mathrm{a}}$ & $27.47 \pm 11.37^{\mathrm{a}}$ & $27.81 \pm 5.99^{\mathrm{a}}$ \\
\hline ALAT activity (UI/mL) & Mean $(20-60 \mathrm{UI} / \mathrm{ml})$ & $18.11 \pm 4.56^{\mathrm{a}}$ & $21.04 \pm 12.15^{\mathrm{a}}$ & $20.10 \pm 5.03^{\mathrm{a}}$ & $22.62 \pm 13.27^{\mathrm{a}}$ \\
\hline
\end{tabular}

a, b: for each parameter (line), mean carrying different superscripts letters are significantly different (Waller-Ducan test, $p<0.05)$. 
Table 5. Prevalences of metabolic disorders in each type of therapy.

\begin{tabular}{|c|c|c|c|c|c|c|}
\hline \multirow{2}{*}{\multicolumn{2}{|c|}{ Parameters/metabolic disorders }} & \multirow{3}{*}{$\begin{array}{c}\text { Naive patient } \\
\text { n (\%) }\end{array}$} & \multicolumn{4}{|c|}{ Types of therapy } \\
\hline & & & \multirow{2}{*}{$\begin{array}{c}\text { Monotherapy } \\
\text { n (\%) }\end{array}$} & \multirow{2}{*}{$\begin{array}{l}\text { Bitherapy } \\
\text { n (\%) } \\
45(67.2 \%)\end{array}$} & \multirow{2}{*}{$\begin{array}{l}\text { Tritherapy } \\
\text { n (\%) }\end{array}$} & \multirow{2}{*}{ P-vaue } \\
\hline & Normal natremia & & & & & \\
\hline \multirow[t]{3}{*}{ Natremia } & Hyponatremia & $3(4.1 \%)$ & $3(3.5 \%)$ & $0(0 \%)$ & $0(0 \%)$ & \multirow{2}{*}{0.611} \\
\hline & Hypernatremia & $21(29.6 \%)$ & $23(27.1 \%)$ & $22(32.8 \%)$ & $8(38.1 \%)$ & \\
\hline & Normal chloremia & $61(85.9 \%)$ & $65(76.5 \%)$ & $49(73.1 \%)$ & $15(71.4 \%)$ & \multirow{3}{*}{0.13} \\
\hline \multirow[t]{3}{*}{ Chloremia } & Hypochloremia & $5(6.8 \%)$ & $14(16.5 \%)$ & $7(10.4 \%)$ & $0(0 \%)$ & \\
\hline & Hyperchloremia & $5(6.8 \%)$ & $6(7.1 \%)$ & $11(16.4 \%)$ & $6(28.6 \%)$ & \\
\hline & Normal kaliemia & $43(60.6 \%)$ & $73(85.9 \%)$ & $50(74.6 \%)$ & $21(100 \%)$ & \multirow{3}{*}{0.000} \\
\hline \multirow[t]{2}{*}{ Kalemia } & Hypokaliemia & $5(6.8 \%)$ & $4(4.7 \%)$ & $7(10.4 \%)$ & $0(0 \%)$ & \\
\hline & Hyperkaliemia & $23(31.5 \%)$ & $8(9.4 \%)$ & $10(14.9 \%)$ & $0(0 \%)$ & \\
\hline \multirow{2}{*}{ Total Cholesterol } & Normal cholesterolemia & $68(95.7 \%)$ & $80(94.1 \%)$ & $64(95.5 \%)$ & $21(100 \%)$ & \multirow{2}{*}{0.711} \\
\hline & Hyper cholesterolemia & $3(4.1 \%)$ & $5(5.9 \%)$ & $3(4.5 \%)$ & $0(0 \%)$ & \\
\hline \multirow{2}{*}{ HDL-cholesterol } & Normal HDL-cholesterolemia & $17(23.9 \%)$ & $64(75.3 \%)$ & $57(85.1 \%)$ & $13(61.9 \%)$ & \multirow{2}{*}{0.000} \\
\hline & Hypo HDL-cholesterolemia & $54(76.1 \%)$ & $21(25.0 \%)$ & $10(14.9 \%)$ & $8(38.1 \%)$ & \\
\hline \multirow{2}{*}{ Triglycerides } & Normal triglyceridemia & $55(77.5 \%)$ & $69(81.2 \%)$ & $56(83.6 \%)$ & $14(66.7 \%)$ & \multirow{2}{*}{0.371} \\
\hline & Hypertriglyceridemia & $16(22.5 \%)$ & $16(18.8 \%)$ & $11(16.4 \%)$ & $7(33.3 \%)$ & \\
\hline \multirow{2}{*}{ LDL-Cholesterol } & Normal LDL-cholesterolemia & $68(95.8 \%)$ & $73(85.9 \%)$ & $94.0 \%(63)$ & $21(100 \%)$ & \multirow{2}{*}{0.44} \\
\hline & Hyper LDL-cholesterolemia & $3(4.1 \%)$ & $12(14.2 \%)$ & $4(6 \%)$ & $0(0 \%)$ & \\
\hline \multirow{3}{*}{ Glycemia } & Normoglycemia & $37(52.1 \%)$ & $42(49.4 \%)$ & $37.3 \%(25)$ & $12(57.1 \%)$ & \multirow{3}{*}{0.003} \\
\hline & Hypoglycemia & $5(6.8 \%)$ & $13(15.3 \%)$ & $12(17.9 \%)$ & $8(38.1 \%)$ & \\
\hline & Hyperglycemia & $29(40.8 \%)$ & $30(35.7 \%)$ & $30(44.8 \%)$ & $1(4.8 \%)$ & \\
\hline \multirow{2}{*}{ ASAT } & Normal ASAT & $70(98.6 \%)$ & $74(87.1 \%)$ & $61(91.0 \%)$ & $21(100 \%)$ & \multirow{2}{*}{0.007} \\
\hline & High ASAT & $1(1.4 \%)$ & $11(12.9 \%)$ & $6(9.0 \%)$ & $0(0 \%)$ & \\
\hline \multirow{2}{*}{ ALAT } & Normal ALAT & $71(100 \%)$ & $83(97.6 \%)$ & $66(98.5 \%)$ & $21(100 \%)$ & \multirow{2}{*}{0.559} \\
\hline & High ALAT & $0(0 \%)$ & $2(2.4 \%)$ & $1(1.5 \%)$ & $0(0 \%)$ & \\
\hline \multirow{2}{*}{ Creatininemia } & Normal creatininemia & $36(50.7 \%)$ & $58(68.2 \%)$ & $39(58.2 \%)$ & $13(61.9 \%)$ & \multirow[b]{2}{*}{0.167} \\
\hline & Hypercreatininemia & $35(49.3 \%)$ & $27(31.8 \%)$ & $28(41.8 \%)$ & $8(38.1 \%)$ & \\
\hline & Hematuria (-) & $66(92.9 \%)$ & $81(95.3 \%)$ & $58(86.6 \%)$ & $21(100 \%)$ & \\
\hline Hematuria & Hematuria (+) & $5(6.8 \%)$ & $4(4.7 \%)$ & $9(13.4 \%)$ & $0(0 \%)$ & 0.066 \\
\hline & Proteinuria (-) & $35(49.3 \%)$ & $55(64.7 \%)$ & $44(65.7 \%)$ & $17(81.0 \%)$ & \\
\hline Proteınurıa & Proteinuria (+) & $36(50.7 \%)$ & $30(35.3 \%)$ & $23(34.3 \%)$ & $4(19.0 \%)$ & 0.034 \\
\hline & Glycosuria (-) & $63(88.7 \%)$ & $76(89.4 \%)$ & $56(83.6 \%)$ & $21(100 \%)$ & \\
\hline Glycosuria & Glycosuria (+) & $8(11.0 \%)$ & $9(10.6 \%)$ & $11(16.4 \%)$ & $0(0 \%)$ & 0.084 \\
\hline
\end{tabular}


On another hand, CCB was significantly associated with increases in blood potassium (odd-ratios $(\mathrm{OR})=8.63, p=0.036)$ and sodium $(\mathrm{OR}=0.20, p=0.037)$ (Table 6). ACE/ARBs was significantly associated with an increase in plasma activity of ASAT (OR $=0.12, p=0.03$ ) whereas diuretics were significantly associated with an increase in ALAT plasma activity $(\mathrm{OR}=0.003, p=0.012)$.

\subsection{Variation of Selected Biochemical Parameters in Naive to Treatment and Treated Patients According to Some Demographic Characteristic of the Population}

The prevalence of biochemical abnormalities have in some cases been influenced by socio-demographic parameters such as level of education, marital status and occupation (Table 7). Thus, the prevalence of hypercreatininemia was significantly higher among married participants than among widowers and celibates $(p$ $=0.001$ ), among civil servants than among private sector workers and retirees ( $p$ $=0.001)$ and among illiterate than in other levels of study $(p=0.017)$. The positive hematuria was not influenced by any of these factors. The same is true for proteinuria, serum sodium and glycosuria although there was a weakly significant effect of educational level on proteinuria $(p=0.019)$ and the marital status on glycosuria $(p=0.013)$. The prevalence of hyperkaliemia was higher among illiterate and primary school children $(p=0.005)$ and retirees than among working people $(p=0.012)$. Hypochloremia was more prevalent among primary level and among married people $(p=0006)$ and among people working in the informal sector more than among civil servants and retired.

Table 6. Odd-ratios of antihypertensive classes on metabolic disorders.

\begin{tabular}{cccc}
\hline Parameters & CCB & Diuretics & ACE/ARBs \\
\hline Hypokalemia & $0.58(p=0.57)$ & $4.63(p=0.12)$ & $0.95(p=0.95)$ \\
Hyperkalemia & $8.63(p=0.036)^{*}$ & $0.50(p=0.41)$ & $0.17(p=0.07)$ \\
Hyponatremia & $0.53(p=0.70)$ & $0.96(p=0.96)$ & $0.00(p=0.99)$ \\
Hypernatremia & $0.20(p=0.037)^{*}$ & $2.74(p=0.13)$ & $2.38(p=0.27)$ \\
Hypochloremia & $0.63(p=0.61)$ & $0.36(p=0.22)$ & $1.41(p=0.70)$ \\
Hyperchloremia & $2.41(p=0.38)$ & $1.41(p=0.69)$ & $1.08(p=0.93)$ \\
Hypercholesterolemia & $14.25(p=0.23)$ & $0.61(p=0.75)$ & $0.48(p=0.68)$ \\
Hypocholesterolemia-HDL & $3.47(p=0.11)$ & $0.99(p=0.98)$ & $0.26(p=0.07)$ \\
Hypercholesterolemia-LDL & $0.11(p=0.11)$ & $1.60(p=0.65)$ & $4.45(p=0.20)$ \\
Hypertriglyceridemia & $1.21(p=0.82)$ & $1.22(p=0.78)$ & $1.27(p=0.75)$ \\
Hypoglycemia & $2.38(p=0.15)$ & $1.44(p=0.50)$ & $0.41(p=0.13)$ \\
Hyperglycemia & $2.92(p=0.14)$ & $0.38(p=0.11)$ & $0.30(p=0.06)$ \\
High ASAT activity & $0.00(p=0.99)$ & $4.22(p=0.16)$ & $0.12(p=0.03)^{*}$ \\
High ALAT activity & $1.12(p=0.99)$ & $0.003(p=0.012)^{*}$ & $0.00(p=0.99)$ \\
\hline
\end{tabular}

$\mathrm{CCB}=$ Calcium Channel Blockers; $\mathrm{ACE} / \mathrm{ARBs}=$ Angiotensin-converting enzyme/Angiotensin II receptor blockers. 
Table 7. Prevalence of biochemical abnormalities in the study population according to some sociodemographic parameters.

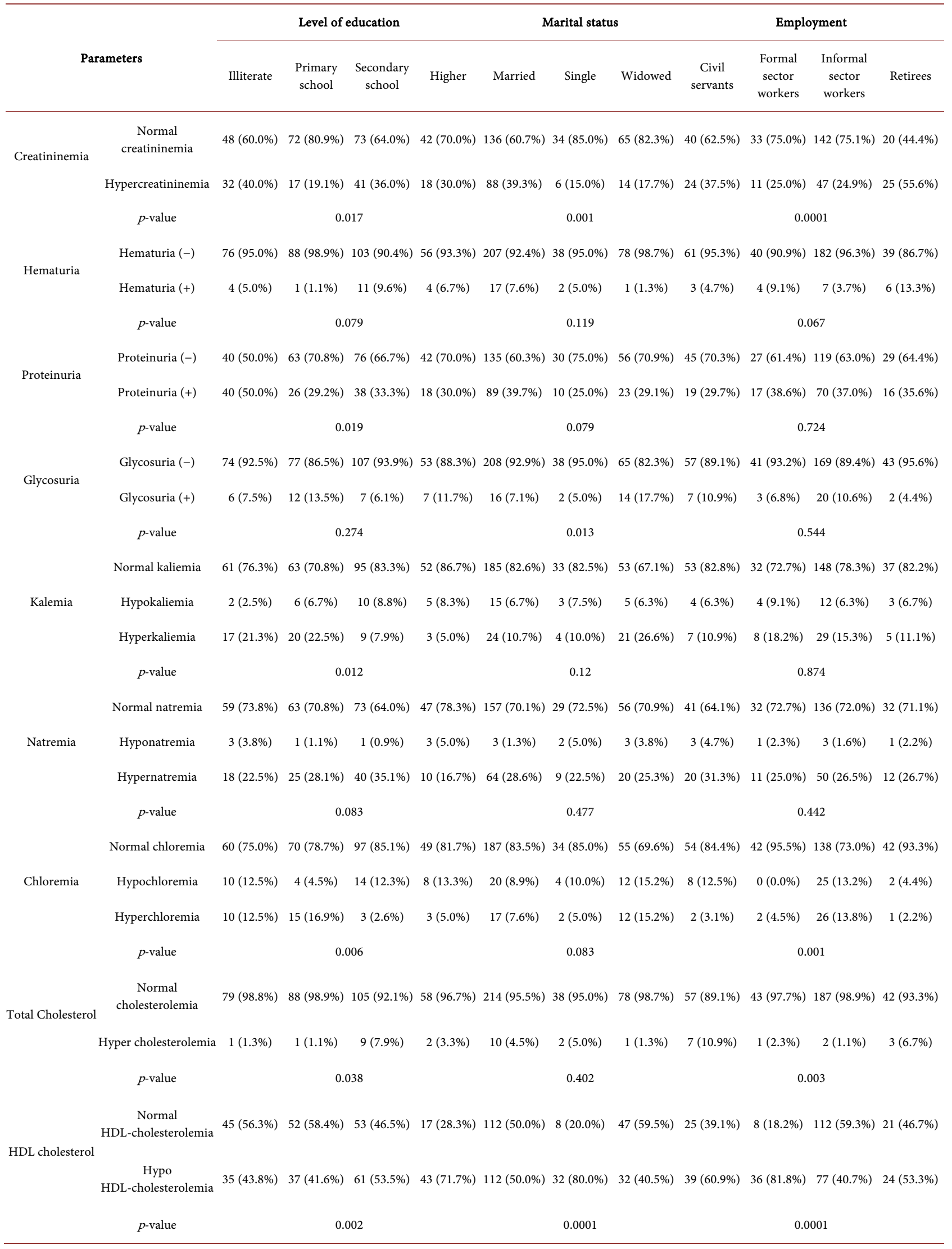




\section{Continued}

\begin{tabular}{|c|c|c|c|c|c|c|c|c|c|c|c|c|}
\hline & $\begin{array}{c}\text { Normal } \\
\text { LDL-cholesterolemia }\end{array}$ & $76(95.0 \%)$ & 88 (98.9\%) & $101(88.6 \%)$ & $56(93.3 \%)$ & $210(93.8 \%)$ & 38 (95.0\%) & 73 (92.4\%) & $57(89.1 \%)$ & $42(95.5 \%)$ & $180(95.2 \%)$ & $41(91.1 \%)$ \\
\hline \multicolumn{13}{|l|}{ LDL-Cholesterol } \\
\hline & $\begin{array}{c}\text { Hyper } \\
\text { LDL-cholesterolemia }\end{array}$ & $4(5.0 \%)$ & $1(1.1 \%)$ & $13(11.4 \%)$ & $4(6.7 \%)$ & $14(6.3 \%)$ & $2(5.0 \%)$ & $6(7.6 \%)$ & $7(10.9 \%)$ & $2(4.5 \%)$ & $9(4.8 \%)$ & $4(8.9 \%)$ \\
\hline & $p$-value & \multicolumn{4}{|c|}{0.027} & \multicolumn{3}{|c|}{0.849} & \multicolumn{4}{|c|}{0.29} \\
\hline \multirow{3}{*}{ Triglycerides } & Hypertriglyceridemia & $13(16.3 \%)$ & $13(14.6 \%)$ & $22(19.3 \%)$ & $8(13.3 \%)$ & $38(17.0 \%)$ & $3(7.5 \%)$ & $15(19.0 \%)$ & $17(26.6 \%)$ & $5(11.4 \%)$ & $26(13.8 \%)$ & $8(17.8 \%)$ \\
\hline & $p$-value & \multicolumn{4}{|c|}{0.724} & \multicolumn{3}{|c|}{0.252} & \multicolumn{4}{|c|}{0.083} \\
\hline & Normal glycemia & $30(37.5 \%)$ & $38(42.7 \%)$ & $74(64.9 \%)$ & $40(66.7 \%)$ & $126(56.3 \%)$ & $26(65.0 \%)$ & $30(38.0 \%)$ & $41(64.1 \%)$ & $31(70.5 \%)$ & $91(48.1 \%)$ & $19(42.2 \%)$ \\
\hline \multirow{2}{*}{ Glycemia } & Hyperglycemia & $43(53.8 \%)$ & $32(36.0 \%)$ & $27(23.7 \%)$ & $17(28.3 \%)$ & $73(32.6 \%)$ & $12(30.0 \%)$ & $34(43.0 \%)$ & $19(29.7 \%)$ & $12(27.3 \%)$ & $69(36.5 \%)$ & $19(42.2 \%)$ \\
\hline & $p$-value & \multicolumn{4}{|c|}{0.0001} & \multicolumn{3}{|c|}{0.018} & \multicolumn{4}{|c|}{0.018} \\
\hline \multirow{2}{*}{ ASAT } & Normal ASAT & $75(93.8 \%)$ & $86(96.6 \%)$ & $104(91.2 \%)$ & $59(98.3 \%)$ & $210(93.8 \%)$ & $40(100.0 \%)$ & $74(93.7 \%)$ & $59(92.2 \%)$ & $44(100 \%)$ & $175(92.6 \%)$ & $45(100 \%)$ \\
\hline & High ASAT & $5(6.3 \%)$ & $3(3.4 \%)$ & $10(8.8 \%)$ & $1(1.7 \%)$ & $14(6.3 \%)$ & $0(0.0 \%)$ & $5(6.3 \%)$ & $5(7.8 \%)$ & $0(0.0 \%)$ & $14(7.4 \%)$ & $0(0.0 \%)$ \\
\hline & $p$-value & \multicolumn{4}{|c|}{0.181} & \multicolumn{3}{|c|}{0.265} & \multicolumn{4}{|c|}{0.069} \\
\hline \multirow{3}{*}{ ALAT } & Normal ALAT & $80(100 \%)$ & $89(100 \%)$ & $111(97.4 \%)$ & $60(100 \%)$ & $221(98.7 \%)$ & $40(100 \%)$ & $79(100 \%)$ & $62(96.9 \%)$ & $44(100 \%)$ & $188(99.5 \%)$ & $45(100 \%)$ \\
\hline & High ALAT & $0(0.0 \%)$ & $0(0.0 \%)$ & $3(2.6 \%)$ & $0(0.0 \%)$ & $3(1.3 \%)$ & $0(0.0 \%)$ & $0(0.0 \%)$ & $2(3.1 \%)$ & $0(0.0 \%)$ & $1(0.5 \%)$ & $0(0.0 \%)$ \\
\hline & $p$-value & 0.108 & & & & & 0.448 & & \multicolumn{4}{|c|}{0.245} \\
\hline
\end{tabular}

The prevalence of hypercholesterolemia (total) was higher among civil servants $(p=0.003)$. HDL hypocholesterol was influenced by all three socio-demographic factors. Thus, more people with higher education level had a low HDL level compared to high school. Primary and illiterate levels presented comparable hypo HDL prevalence $(p=0.002)$. Singles exhibited lowest HDL levels $(p=$ $0.0001)$, as did private and public sector workers $(p=0.0001)$. The prevalence of elevated LDL and triglycerides were not affected significantly influenced by these factors. Hyperglycemia was observed more in the illiterate $(p=0.0018)$, in the married people $(p=0.0001)$ and in the people working in the informal sector $(\mathrm{p}=0.0018)$. Hypoglycemia was most noted in people at the primary level, in married people and in people working in the informal sector. The prevalences of ASAT and ALT activity abnormalities were not affected by the socio-demographic parameters considered.

\section{Discussion}

In the present study, more women than men were normotensive, and more women than men were on treatment, while the proportion of treatment-naive men was almost the same as in women. A previous study showed that men have a higher incidence of hypertension compared to females of the same age up to 60 years [18]. Moreover, more than half of the participants in this study do not regularly participate in sport. 
Physical activity is one of the essential hygiene and nutrition measures for the management of arterial hypertension, while having beneficial effects that go beyond the reduction of cardiovascular events and mortality [19]. However, in the present study, more than half of the participants stated that they did not engage in regular physical activity. We would be quite right to believe that this lack of physical activity contributes to their situation. Arterial hypertension can appear at any age in life. Arterial hypertension (hypertension), the most common disease of the elderly, affects almost half of people over 65 years of age. Changes in the structure of the failures explain this state of affairs [20]. The results obtained in the present study are in agreement with this assertion. In fact, the majority of hypertensive patients were recruited from the age of 50 , with the age group 50 - 60 was most represented. The greatest number of patients naive to treatment and under treatment was recruited in this same age group.

The married and widow were significantly more represented among hypertensive patients. Only a few singles were hypertensive in both the treatment-naive and the treatment-naive groups. On the other hand, the hypertensive participants were mainly recruited from married and widowed persons. According to a study conducted by Birditt et al. [21], this result can be explained by negative relationships in the couple leading to stress that directly affects the cardiovascular system. These findings however, contrast with those of Ramezankhani et al. [22] who concluded in their study that never having been married is an important risk factor for hypertension and cardiovascular disease. The distribution of participants by type of job revealed a significant difference between groups $(p<0.001)$. Although the majority of the non-hypertensive participants were informal sector workers, it was also in this group that the hypertensives were most numerous. This also justifies that they were the most numerous under treatment and amount naive to treatment. However, it has been established that working under stress increases blood pressure. Although in the informal sector physical labor is generally important, its effect would be mitigated by the poor feeding conditions and the stress the worker are exposed.

Level of education was identified as a significant factor in hypertension. People with a higher level of education were less represented in hypertensive patients. A study conducted in China by Wang et al. [23] showed that a low level of education was correlated with a greater risk of hypertension. The mean BMI in hypertensive patients on treatment or not, were not significantly different from that in non-hypertensive patients. However, the prevalence of overweight and obesity was greater in hypertensive participants. According to Landi et al. [24], body index mass is closely related to hypertension as a cause of this disease and may have a direct effect on blood pressure, independent of other clinical risk factors. In the study population, this is certainly due to non-compliance with the nutrition and hygienic measures that patients should comply with. It has been found that very few practice regular physical activity and a good fringe consumes alcohol and smokes. It seems important to us that the follow-up of the 
patients is accompanied by a good nutritional education because although almost all affirmed to consume fruits and vegetables in sufficient quantities, one can wonder if despite everything their diet is not unbalanced. Alcohol is the third factor in hypertension after age and body weight because there is a positive link between the level of alcohol consumption and hypertension. The physiopathological mechanisms of alcohol action are multiple: direct action of alcohol on smooth muscle cells, indirect action by stimulation of hormones involved in the regulation of sodium hydroxide and arterial vasoconstriction of the organism.

In the follow-up of hypertensive patients, particular attention is paid to cardiac, renal and hepatic functions. The laboratory tests include determination of some electrolytes in the blood. The fluid and electrolyte balance plays a major role in the homeostasis of the human body. Its regulation is very fine through complex mechanisms which largely involve the kidney and the lungs. The most abundant anion is undoubtedly chlorine, which is classically the companion of sodium in most transmembrane or inter-compartmental exchanges, the preservation of electro neutrality being a major physiological imperative [25], both ions being mainly provided by food. Some epidemiological data suggests that excessive intake of $\mathrm{Cl}^{-}$promotes an increase in blood pressure [26].

Paradoxically, other studies tend to establish that high serum levels of this anion are associated with a decrease in mortality and cardiovascular risk [27]. In other works, $\mathrm{Cl}^{-}$would be able to influence these important prognostic variables, regardless of blood pressure or the biological pathways involved in the exchange of $\mathrm{Na}^{+}$and bicarbonates [25]. A few hypertensive and monotherapy participants were in a condition of hyponatremia. It is the most common electrolyte disorder and may be associated with increased morbidity and mortality. Diuretic use is one of the most common causes. Hypernatremia is defined as a plasma sodium concentration above the laboratory standard, generally $>145 \mathrm{mmol} / 1$. The proportion of hypernatremia patients was relatively high in almost all treatment groups.

Within the framework of the initial assessment or the follow-up of hypertensive patients the following laboratory tests are recommended: serum creatinine and estimation of glomerular filtration rate, detection of proteinuria, hematuria, and determination of serum potassium, glycemia, cholesterol total and HDL-cholesterol, LDL-cholesterol and ECG at rest [28]. Most of these parameters were evaluated, in relation with socio-demographic factors. High blood pressure is the main cardiovascular risk factor having consequences on kidney function. Drug treatment may also have adverse effects on kidneys and livers. Despite the effectiveness of anti-hypertensives in reducing mortality and morbidity, individuals on anti-hypertensive therapy remain at high risk of metabolic disorders, especially if blood pressure is poorly controlled [29]. In the present study, we determined risk factors of hypertension and the metabolic disorders associated with anti-hypertensive therapies.

Dysfunction of the liver, the cardinal organ of nutrient and xenobiotic meta- 
bolism, may be the cause of high blood pressure or its maintenance. In the present study, the transaminase levels remained within the normal range although there was a significant increase in ASAT in hypertensive patients on treatment compared to hypertensive patients naive to treatment. This shows that the risks of liver damage due to treatment are lower.

Associated with dyslipidemia, hypertension is a major risk factor for cardiovascular disease. This is the reason why variations in blood lipid levels must be taken into account when monitoring hypertension patients. But not all lipids have the same value. HDL, known as "good cholesterol" collects excess cholesterol and returns it to the liver where it is transformed before being eliminated, while LDL carries cholesterol from the liver to all cells. But these LDL-cholesterols can accumulate and contribute to the formation of atheroma plaques which gradually clog the arteries. In the present study, the average levels of these two cholesterols were kept within the normal range. However, more normotensive patients experienced low HDL values compared to hypertensive ones. In addition, people on tri-therapy were more likely to have low HDL values, resulting in a low cardiovascular risk.

A fringe of the study population had hypoglycemia and appeared in all groups. Blood pressure is believed to rise after hypoglycemia by activation of the sympathetic nervous system. It also causes an increase in heart rate, reduced peripheral arterial resistance and increased myocardial contractility [30] [31]. In the group of non-hypertensive patients, the percentage of diabetics was higher than in the hypertensive groups under treatment. Hypertension and diabetes have common causes including sedentary lifestyle and obesity. People with high blood pressure have a higher risk of developing diabetes, and people with diabetes have an increased risk of high blood pressure as well. In the group of non-hypertensive patients, the percentage of diabetics was higher than in the hypertensive groups under treatment. Hypertension and diabetes have common causes including sedentary lifestyle and obesity. People with high blood pressure have a higher risk of developing diabetes, and people with diabetes have an increased risk of high blood pressure as well [32]. This may justify the relatively large proportion of diabetics among those naive to treat in virtually all groups

\section{Conclusion}

Calcium Channel Blockers were significantly associated with increases in blood potassium and sodium. Angiotensin-converting enzyme/Angiotensin II receptor blockers were significantly associated with an increase in plasma activity of ASAT whereas Diuretics were significantly associated with an increase in ALAT plasma activity. Dual therapies were associated with the highest frequencies of hypercreatininemia and hyperglycemia whereas hypocholesterolemia HDL was most observed in hypertensive patients on triple therapy. The different therapies resulted in very low frequencies of abnormal liver profiles (in general almost all below 10\%); suggesting that the risks of liver damage due to hypotensive drugs 
are low. Tritherapy had the most beneficial effects on the different profiles, with no cases of hyperkalemia, glycosuria, hypochloremia, hematuria, hyponatremia, total hypercholesterolemia, ALAT and ASAT hyperactivity. Triple therapy should be recommended as it has the most beneficial effects on metabolic parameters in the study population.

\section{Conflicts of Interest}

The authors declare no conflicts of interest regarding the publication of this paper.

\section{References}

[1] Harvey, J.M. and Beevers, D.G. (1990) Biochemical Investigation of Hypertension. Annals of Clinical Biochemistry, 4, 287-296.

https://doi.org/10.1177/000456329002700403

[2] Dahlof, B. (2007) Prevention of Stroke in Patients with Hypertension. American Journal of Cardiology, 100, S17-S24. https://doi.org/10.1016/j.amjcard.2007.05.010

[3] Oparil, S., Acelajado, M.C., Bakris, G.L., Berlowitz, D.R., Cífková, R., Dominiczak, A.F., Grassi, G., Jordan, J., Poulter, N.R., Rodgers, A. and Whelton, P.K. (2018) Hypertension. Nature Reviews Disease Primers, 4, Article No. 18014. https://doi.org/10.1038/nrdp.2018.14

[4] Garcia-Puig, J., Luis, M.R., Manuel, L., Jaime, F., Rafael, O., Rafael, D. and Avant, S.G.I. (2006) Glucose Metabolism in Patients with Essential Hypertension. American Journal of Medicine, 119, 318-326. https://doi.org/10.1016/j.amjmed.2005.09.010

[5] Izzo, R., de Simone, G., Trimarco, V., Gerdts, E., Giudice, R., Vaccaro, O., De Luca, N. and Trimarco, B. (2013) Les dommages causés aux organes cibles par l'hypertension permettent de prévoir le diabète sucré incident. European Heart Journal, 34, 3419-3426. https://doi.org/10.1093/eurheartj/eht281

[6] Laurent, S. (2017) Antihypertensive Drugs. Pharmacological Research, 124, 116-125. https://doi.org/10.1016/j.phrs.2017.07.026

[7] Whelton, P.K., Carey, R.M., Aronow, W.S., Casey, D.E., Collins, K.J., Himmelfarb, C.D., DePalma, S.M., Gidding, S., Jamerson, K.A., Jones, D.W., MacLaughlin, E.J., Muntner, P., Ovbiagele, B., Smith, S.C., Spencer, C.C., Stafford, R.S., Taler, S.J., Thomas, R.J., Williams, K.A., Williamson, J.D. and Wright, J.T. (2018) 2017 ACC/AHA/AAPA/ABC/ACPM/AGS/APhA/ASH/ASPC/NMA/PCNA Guideline for the Prevention, Detection, Evaluation, and Management of High Blood Pressure in Adults: A Report of the American College of Cardiology/American Heart Association Task Force on Clinical Practice Guidelines. Journal of the American College of Cardiology, 71, e127-e248.

[8] Pimenta, E. and Oparil, S. (2008) Fixed Combinations in the Management of Hypertension: Patient Perspectives and Rationale for Development and Utility of the Olmesartan-Amlodipine Combination. Vascular Health and Risk Management, 4, 653-654. https://doi.org/10.2147/VHRM.S2586

[9] Rubio-Guerra, A.F., Castro-Serna, D., Elizalde-Barrera, C.I. and Ramos-Brizuela, L.M. (2009) Current Concepts in Combination Therapy for the Treatment of Hypertension: Combined Calcium Channel Blockers and RAAS Inhibitors. Integrated Blood Pressure Control, 2, 55-62. https://doi.org/10.2147/IBPC.S6232

[10] Volpe, M., Gallo, G. and Tocci, G. (2018) Is Early and Fast Blood Pressure Control 
Important in Hypertension Management? International Journal of Cardiology, 254, 328-332. https://doi.org/10.1016/j.ijcard.2017.12.026

[11] Wald, D.S., Law, M., Morris, J.K., Bestwick, J.P. and Wald, N.J. (2009) Combination Therapy Versus Monotherapy in Reducing Blood Pressure: Meta-Analysis on 11,000 Participants from 42 Trials. American Journal of Medicine, 122, 290-300. https://doi.org/10.1016/j.amjmed.2008.09.038

[12] Burnier, M. (2015) Antihypertensive Combination Treatment: State of the Art. Current Hypertension Reports, 17, Article No. 51. https://doi.org/10.1007/s11906-015-0562-0

[13] Elliott, W.J. and Meyer, P.M. (2007) Incident Diabetes in Clinical Trials of Antihypertensive Drugs: A Network Meta-Analysis. The Lancet, 369, 201-207. https://doi.org/10.1016/S0140-6736(07)60108-1

[14] Koh, K.K., Quon, M.J., Shan, S.H., Lee, Y., Kim, S.J., Koh, Y. and Shin, E.K. (2010) Distinct Vascular and Metabolic Effects of Different Classes of Antihypertensive Drugs. International Journal of Cardiology, 140, 73-81. https://doi.org/10.1016/j.ijcard.2008.11.017

[15] Bell, D.S. (2005) Optimizing Treatment of Diabetes and Cardiovascular Disease with Combined Alpha,Beta-Blockade. Current Medical Research and Opinion, 21, 1191-1200. https://doi.org/10.1185/030079905X53306

[16] Sica, D.A. (2007) Antihypertensive Therapy and Its Effects on Potassium Homeostasis. Journal of Clinical Hypertension, 8, 67-73. https://doi.org/10.1111/j.1524-6175.2006.05139.x

[17] Friedewald, W.T., Levy, R.I. and Fredrickson, D.S. (1972) Estimation of the Concentration of Low-Density Lipoprotein Cholesterol in Plasma without Use of the Preparative Ultracentrifuge. Clinical Chemistry, 18, 499-502. https://doi.org/10.1093/clinchem/18.6.499

[18] Fryar, C.D., Ostchega, Y., Hales, C.M., Zhang, G. and Kruszon-Moran, D. (2017) Hypertension Prevalence and Control among Adults: United States, 2015-2016. NCHS Data Brief, No. 289, National Center for Health Statistics, Hyattsville, MD, 1-8.

[19] Cornelissen, V. and Fagard, R. (2005) Effects of Endurance Training on Blood Pressure, Blood Pressure-Regulating Mechanisms, and Cardiovascular Risk Factors. Hypertension, 46, 667-675. https://doi.org/10.1161/01.HYP.0000184225.05629.51

[20] Longo-Mbenza, B. (1995) Diabète sucré et maladies cardiovasculaires. Cardiologie Tropicale, 21, 37-44.

[21] Birditt, K.S. Newton, N. and Hope, S. (2014). Implications of Marital/Partner Relationship Quality and Perceived Stress for Blood Pressure among Older Adults. The Journals of Gerontology, Series B: Psychological Sciences and Social Sciences, 69, 188-198. https://doi.org/10.1093/geronb/gbs123

[22] Ramezankhani, A., Azizi, F. and Hadaegh, F. (2019) Associations of Marital Status with Diabetes, Hypertension, Cardiovascular Disease and All-Cause Mortality: A Long Term Follow-Up Study. PLoS ONE, 14, e0215593. https://doi.org/10.1371/journal.pone.0215593

[23] Wang, T.J. and Vasan, R.S. (2005) Epidemiology of Uncontrolled Hypertension in the United States. Circulation, 112, 1651-1662. https://doi.org/10.1161/CIRCULATIONAHA.104.490599

[24] Landi, F, Calvani, R, Picca, A, Tosato, M, Martone, AM, Ortolani, E, Sisto, A, D’Angelo, E, Serafini, E, Desideri, G, Fuga, MT and Marzetti, E. (2018) Body Mass Index Is Strongly Associated with Hypertension: Results from the Longevity 
Check-Up 7+ Study. Nutrients, 10, 1976. https://doi.org/10.3390/nu10121976

[25] McCallum, J.L., Cook, P.G. and Simmons, C.T. (2014) Limitations of the Use of Environmental Tracers to Infer Groundwater Age. Ground Water, 52, 239-250.

[26] McCallum, L., Lip, S. and Padmanabhan, S. (2015) The Hidden Hand of Chloride In Hypertension. Pflügers Archiv: European Journal of Physiology, 467, 595-603. https://doi.org/10.1007/s00424-015-1690-8

[27] McCallum, L., Jeemon, P., Hastie, C.E., Patel, R.K., Williamson, C., Redzuan, A.M., Dawson, J., Sloan, W., Muir, S., Morrison, D., McInnes, G.T., Freel, E.M., Walters, M., Dominiczak, A.F., Sattar, N. and Padmanabhan, S. (2013) Serum Chloride Is an Independent Predictor of Mortality In Hypertensive Patients. Hypertension, 62, 836-843. https://doi.org/10.1161/HYPERTENSIONAHA.113.01793

[28] Reis, R.S., Benseñor, I.J. and Lotufo, P.A. (1999) Laboratory Assessment of the Hypertensive Individual. Value of the Main Guidelines for High Blood Pressure. Arquivos Brasileiros de Cardiologia, 73, 201-210. https://doi.org/10.1590/S0066-782X1999000800008

[29] Rosendorff, C., Black, H., Cannon, C., Gersh, B., Gore, J. and Izzo, J. (2007) Treatment of Hypertension in the Prevention And Management of Ischemic Heart Disease: A Scientific Statement from the American Heart Association Council for High Blood Pressure Research and the Councils on Clinical Cardiology and Epidemiology and Prevention. Circulation, 115, 2761-2788. https://doi.org/10.1161/CIRCULATIONAHA.107.183885

[30] Frier, B.M., Guntram, S. and Heller, S.R. (2011) Hypoglycemia and Cardiovascular Risks. Diabetes Care, 34, S132-S137. https://doi.org/10.2337/dc11-s220

[31] Feldman-Billard, S., Massin, P., Meas, T., Guillausseau, P.J. and Heron, E. (2010) Hypoglycemia Induced Blood Pressure Elevation in Patients with Diabetes. Archives of Internal Medicine, 170, 829-831. https://doi.org/10.1001/archinternmed.2010.98

[32] de Boer, I.H., Bangalore, S., Benetos, A., Davis, A.M., Michos, E.D., Muntner, P., Rossing, P., Zoungas, S. and Bakris, G. (2017) Diabetes and Hypertension: A Position Statement by the American Diabetes Association. Diabetes Care, 40, 1273-1284. https://doi.org/10.2337/dci17-0026 